\title{
O PANORAMA LINGÜÍSTICO BRASILEIRO: A COEXISTÊNCIA DE LIINGGUAS MINORITÁRIAS COM O PORTUGUÊS
}

RESUMO: Este trabalho apresenta, de forma resumida, uma revisão do panorama linguiístico no Brasil, numa abordagem que discute a situação das línguas minoritárias brasileiras. Especial atenção é dada ao seu desenvolvimento ao longo do tempo. Procura mostrar também o estado atual das línguas indígenas e das línguas dos imigrantes em território brasileiro. Por fim, é feita aqui uma reflexão sobre a diversidade linguiística no Brasil.

PALAVRAS-CHAVE: Multilingüiismo; línguas minoritárias; línguas indígenas; línguas de imigrantes.

\section{INTRODUÇÃO}

realidade multilingual num mesmo território nacional tem
sido um fato a permitir amplas análises no que concerne
ao contato de línguas, com suas implicações na esfera das
questões socioculturais.

Países oficialmente multilínguies, como a Suíça (quatro línguas oficiais), ou oficialmente bilínguies, como o Canadá (duas línguas oficiais), apresentam uma situação em que o convívio das línguas é garantido por políticas sociais.

Entretanto, é bem maior o número de países onde a existência de várias línguas no mesmo território nacional é assinalada pelo maior

Universidade Federal de Minas Gerais. 
prestígio social que uma passa a ter em detrimento das outras. Situações assim estabelecidas ensejam reações as mais diversas por parte das comunidades afetadas. Na Argélia, é possível observar o conflito entre os berberofones e o Estado argelino com sua política de arabização; na Bélgica, verifica-se a oposição entre as comunidades flamengas e "Wallone"; ao lado disso, vemos ainda numerosas lutas pela independência nacional integrando reivindicações linguiísticas como, por exemplo, o que se passa no Sri Lanka com os "tamoues", ou na Espanha com os bascos (Vermes \& Boutet, 1989, p. 8).

Considerando-se a possibilidade de uma comunidade lingiuística fragmentar-se em outras comunidades lingüísticas menores, percebemos que tal situação oferece ao usuário da língua condições de transitar a um só tempo por vários grupos linguiísticos, isto é, experimentar as variações estabelecidas em seu código linguiístico ou utilizar, em caso de comunidade plurilíngüie, mais de um sistema de signos linguiísticos.

A imagem de unidade da língua nacional brasileira propiciou, de certa forma, uma imagem distorcida do panorama lingüístico do Brasil, como um enorme país monolínguie, dominado pela língua portuguesa em toda a sua extensão, fato que esconde a sua realidade plurilínguie, marcada pela coexistência de várias línguas com o português.

A história do Brasil, ao longo de pouco mais de 500 anos, revela o entrecruzamento de diversos povos, gerando uma identidade pluriétnica na formação da sociedade brasileira. Desde o descobrimento do Brasil até hoje, sempre tivemos um multilingüismo estabelecido no território nacional. Primeiramente, com a grande diversidade de línguas indígenas já existentes em terras brasileiras. Com o processo de colonização, chega ao Brasil a língua portuguesa e, em seguida, com o tráfico de escravos, chegam diversas línguas de origem africana. Mais tarde, graças às campanhas imigratórias desenvolvidas pelo governo brasileiro, chegam levas de imigrantes, fixando aqui línguas de origem européia e asiática. 


\section{LÍNGUAS MINORITÁRIAS NO BRASIL}

Por línguas minoritárias designamos aquelas faladas por grupos de pessoas num país que tem por oficial uma língua diferente, isto é, são línguas naturais, não criadas artificialmente, tradicionalmente usadas por parcelas da população de um país, e que não se confundem com dialetos da língua oficial. A grande maioria das línguas existentes no mundo encontra-se nessa situação. De acordo com dados apontados por Crystal (2000), mais da metade das línguas faladas em nosso planeta não conta, cada uma, com mais de 10.000 falantes. Alguns países apresentam situações de grande complexidade, como é o caso da Indonésia, por exemplo, cuja extensão territorial abarca perto de 3.000 ilhas, onde coexistem cerca de 200 línguas (Calvet, 1996). Na União Européia, ao lado das línguas oficiais dos países membros, convivem 50 línguas minoritárias (EBNER, 2000).

É nesse contexto que situamos o panorama linguiístico brasileiro. Na Constituição Federal de 1988, em seu Artigo 13, vimos a língua portuguesa ser enunciada como "o idioma oficial da República Federativa do Brasil". Como língua oficial de nosso país, o português é a língua obrigatória em todos os documentos e atos oficiais e no ensino de modo geral. Isto não implica, entretanto, uma confluência automática entre língua oficial e língua materna, considerando-se o multilinguiismo existente em território brasileiro.

Os trabalhos recentemente desenvolvidos sobre a história das idéias linguiísticas no Brasil mostram que o nosso país representa, indubitavelmente, um dos campos mais vastos e praticamente inexplorados para o estudo de minorias linguiísticas como de línguas em contato. São línguas distintas coexistindo em uma mesma comunidade nacional, estando o português, língua majoritária, a conviver não só com as línguas indígenas, mas também com as línguas dos imigrantes que aqui se fixaram: o polonês, o alemão, o ucraniano, o italiano, o japonês, o coreano, o chinês etc. 


\section{AS LÍNGUAS INDÍGENAS}

Atualmente, em conformidade com as estatísticas do Conselho Indigenista Missionário (CIMI), há cerca de 230.000 índios no Brasil, distribuídos em 220 etnias (Gomes, 1988, p. 24), falando aproximadamente 180 línguas distintas (Rodrigues, 1993).

A população indígena no Brasil diminuiu drasticamente já no primeiro século de colonização, em decorrência do extermínio dos índios situados na costa brasileira, sobretudo do Rio de Janeiro a Pernambuco. Antes do início da colonização pelos europeus, a diversidade das línguas existentes no Brasil refletia-se em um número de aproximadamente 1.200 línguas faladas por diversos povos indígenas, segundo dados levantados por Rodrigues (1993), o que significa que apenas $15 \%$ teriam sobrevivido.

Entretanto, indícios detectados por antropólogos brasileiros (Gomes, 1988, p. 17) apontam crescimento, nas últimas décadas do século XX, das populações indígenas sobreviventes, surpreendendo as expectativas alarmantes que sempre existiram. Pode-se notar tal crescimento em alguns povos como os Guarani, Terena, Guajajara, Tikuna e outros mais, que contam com mais de duzentos anos de contato com o mundo luso-brasileiro.

No período colonial brasileiro, a emigração contínua de portugueses, na sua maioria de origem rural, para o Brasil, onde ficaram culturalmente isolados, assim como seus descendentes, propiciou, ao longo de aproximadamente duzentos anos, uma experiência linguiística um tanto dissociada da que concomitantemente se realizava em Portugal, refletindo o que resultava do bilingüismo entre o português europeu e o tupinambá, uma língua geral de intercurso, originária dos índios Tupi, estudada, descrita e ensinada em tratados gramaticais pelos jesuítas, tornando-se de fato "a língua mais falada na costa do Brasil".

Até meados do século XVIII ambas as línguas eram utilitárias e prestigiosas, conquanto se reconheça a predominância do uso da língua tupinambá, também chamada tupi antigo ou língua brasílica (Rodrigues, 1986, p. 21). 
Filol. lingüíst. port., n. 9, p. 43-73, 2007.

Durante os três séculos do período colonial brasileiro, surgiram importantes trabalhos sobre algumas línguas indígenas do Brasil, merecendo especial destaque os produzidos, por padres jesuítas, sobre três dessas línguas:

a) a Arte de gramática da língua mais usada na costa do Brasil, de José de Anchieta, em 1595;

b) a Arte da língua brasilica, de Luís Figueira, em 1621;

c) a Arte de gramática da língua brasílica da Nação Kiriri, de Luís Vincencio Mamiani, em 1699.

Também foi produzido, pelo padre Manuel Viegas, com o auxílio do padre Anchieta, um trabalho (gramática, vocabulário e catecismo), que ficou manuscrito, sobre a língua dos maramonin ${ }^{1}$ ou guarulho, o qual, por não ter sido publicado, se perdeu ao longo do tempo.

As gramáticas de Anchieta, Figueira e Mamiani tinham motivação pedagógica e faziam a descrição da língua com método pautado no instrumental descritivo próprio para a língua latina.

Das cerca de 180 línguas indígenas faladas atualmente no Brasil, com aproximadamente quarenta e três famílias e dois troncos (Rodrigues, 1993), a maior parte situa-se na Amazônia brasileira. A classificação científica das línguas indígenas é feita levando-se em conta o parentesco genético, isto é, tem-se uma família lingüística quando se tem um conjunto de línguas para as quais há evidências de serem provenientes de uma mesma língua ancestral. Nessa mesma linha, tem-se um tronco lingüístico quando se reconhecem, entre familias lingüísticas, traços genéticos comuns (propriedades linguiísticas), indicando uma origem comum mais remota. No Brasil, os estudos realizados até hoje reconhecem o tronco tupi, com dez famílias, e o tronco macro-jê, de caráter ainda hipotético, compreendendo doze famílias.

Cf. Rodrigues, A. D. (2005) Sobre as línguas indígenas e sua pesquisa no Brasil. Ciência e Cultura, 57, 2, p. 35-8. 
Presentemente, a Amazônia brasileira é a área de maior concentração de populações indígenas no Brasil. São mais de cem línguas indígenas, cujos usuários foram capazes de preservá-las, mesmo em condições históricas adversas. Muitos desses falantes são monolínguies em línguas indígenas e outros são bilínguies, com diferentes níveis de competência na língua portuguesa. Entre as línguas da Amazônia brasileira, cumpre destacar o papel de grande importância que ocupou a língua nheengatu, também chamada língua geral, junto às povoações e cidades de toda a região, como salienta Freire:

\footnotetext{
Durante dois séculos e meio, índios, mestiços, negros e portugueses trocaram experiências e bens, e desenvolveram a maioria de suas práticas sociais, trabalhando, narrando, cantando, rezando, amando, sonhando, sofrendo, reclamando, rindo e se divertindo nessa língua indígena que se firmou como língua supra-étnica, difundida amplamente pelos missionários, por meio da catequese. Contou para isso, inicialmente, com o apoio do próprio Estado monárquico que, depois, em meados do século XVIII, modificando sua política, proibiu a língua geral e tornou obrigatório o uso da língua portuguesa. No entanto, apesar da decisão política, a língua geral continuou crescendo, e entrou no século XIX como língua majoritária da população regional. Com a adesão do Grão-Pará à Independência do Brasil, cessou sua expansão, e ela começou a se retrair progressivamente, abandonando o espaço urbano e as próprias margens do rio Amazonas, cedendo sua hegemonia, só em meados do sáculo XIX, para a língua portuguesa. (Freire, 2004, p. 17)
}

A constituição brasileira, promulgada em 1988, consolidou direitos conquistados pelos povos indígenas do Brasil. Tal fato tem permitido uma série de ações voltadas para a revitalização das identidades, dos costumes, das línguas, das crenças e tradições indígenas.

Fato digno de nota é o que aconteceu no município de São Gabriel da Cachoeira, no estado do Amazonas. Em sessão realizada em 22 de novembro de 2002, a Câmara Municipal de São Gabriel da Cachoeira aprovou o projeto de lei do vereador índio Kamico Baniwa, elaborado com assessoria do Instituto de Investigação e Desenvolvimento em Política Linguiística (IPOL), declarando, pela lei 145/2002, a co-oficialização das línguas indígenas nheengatu, tukano e baniwa, à língua portuguesa. Com essa lei municipal, que recebeu 
Filol. lingüíst. port., n. 9, p. 43-73, 2007.

prazo de cinco anos para implementação, fica estabelecido que a condição de língua co-oficial obriga o município a adotar procedimentos como:

a) prestar os serviços públicos básicos de atendimento ao público nas repartições públicas na língua oficial e nas três línguas co-oficiais, oralmente e por escrito;

b) produzir a documentação pública, bem como as campanhas publicitárias institucionais na língua oficial e nas três línguas co-oficiais;

c) incentivar a apoiar o aprendizado e o uso das línguas co-oficiais nas escolas e nos meios de comunicações etc.

No quadro geral das línguas indígenas brasileiras, importa ressaltar a existência de línguas isoladas que até hoje não foram inteiramente documentadas, através de estudos descritivos. As chamadas línguas isoladas são aquelas que não revelam parentesco genético com nenhuma outra língua conhecida.

Em certo sentido, as línguas isoladas representam tipos linguiísticos únicos, em contraste com as línguas de uma família, cujas características básicas se reencontram em outras línguas da mesma família. Embora toda língua tenha propriedades únicas, que se perdem quando essa língua desaparece sem ter sido devidamente documentada, essa perda é muito maior quando se extingue uma língua isolada. (...) É por isso extremamente preocupador o fato de que a maioria das línguas isoladas ainda faladas no Brasil se encontre ameaçada de desaparecimento, em alguns casos realmente iminente dado o extremamente diminuto número de pessoas que ainda as falam, e que várias delas não tenham sido estudadas de modo nenhum. (Rodrigues, 1986, p. 93-4)

As comunidades linguiísticas, formadas por grupos indígenas brasileiros, são demograficamente muito frágeis, com baixas concentrações de população por língua. A densidade populacional média é de menos de duzentos falantes por língua. Algumas, provavelmente umas cinquienta, são faladas por menos de cem pessoas, das quais nove contam com apenas vinte falantes (Freire, 2004). Os maiores contingentes ficam entre dez mil e vinte mil índios (Guarani, Tikuna, Terena, Makuxi, Kaingang). 


\section{AS LÍNGUAS DOS IMIGRANTES AFRICANOS}

No Brasil, quando se fala em povos imigrantes, comumente a referência recai sobre os imigrantes de origem européia ou asiática. Contudo, os povos africanos que vieram para o Brasil também eram imigrantes. Eram, como se sabe, imigrantes forçados. Desse modo, podemos identificar dois tipos de imigrantes em solo brasileiro: o dos forçados (povos africanos submetidos à escravidão), que chegaram desde o início do período colonial, e o dos espontâneos (povos de origem asiática e européia), que chegaram bem mais tarde, já no século XIX.

Em 1538, chegaram os primeiros africanos ao Brasil, para, ao fim de poucas gerações, começar sistematicamente a substituir nos trabalhos forçados o índio que, ao longo do século XVII, teve sua população da costa brasileira bastante reduzida, por razões historicamente conhecidas.

O tráfico de escravos, durante o período colonial brasileiro, prolongou-se por mais de três séculos sucessivos (séculos XVI, XVII e XVIII, principalmente), o que permitiu a introdução no Brasil de aproximadamente quatro milhões de africanos, de origem diversa. Essa diversidade abarca os originários de duas regiões da África subsaariana: a região banto, situada ao longo da extensão sul da linha do equador, e a região oeste africana ou "sudanesa", que abrange territórios que vão do Senegal à Nigéria (Pessoa de Castro, 2001). Essa diversidade de origem pode ser ainda dimensionada pelos vários ciclos que marcaram o longo período do tráfico de escravos: o ciclo da Guiné (século XVI), com os africanos "sudaneses"; o ciclo do Congo e de Angola (século XVII), com os "bantos"; o ciclo da costa da Mina e da baía do Benim (século XVIII), novamente com os "sudaneses". Durante a primeira metade do século XIX, ainda chegaram ao país africanos de várias regiões da África, predominantemente os originários de Angola e Moçambique.

Em conformidade com Greenberg (1963), as cerca de 1900 línguas existentes na África podem ser distribuídas em quatro tron- 
cos linguiísticos: congo-cordofaniano, nilo-saariano, afro-asiático e coissã. O tronco congo-cordofaniano se divide em duas grandes famílias: niger-congo e cordofaniano. É na primeira, que engloba mais de mil línguas, que vamos situar os ramos banto e kwa, representando as línguas africanas que chegaram ao Brasil. Não se pode hoje, diante desse quadro da história do Brasil, afirmar com precisão o número de línguas que aportaram aqui. Entretanto, é importante ressaltar que, na África, a região banto compreende atualmente um grupo de 300 línguas, faladas em 21 países (Pessoa de Castro, 2001). No Brasil, em meio às línguas dos "bantos", as que apresentavam maior número de falantes eram o quicongo, o quimbundo e o umbundo. O quicongo é falado na República Popular do Congo, na República Democrática do Congo e no norte de Angola. O quimbundo é a língua da região central de Angola. O Umbundo é falado no sul de Angola e em Zâmbia (Pessoa de Castro, 2001). Quanto às línguas "sudanesas", da região oeste africana, as mais importantes no Brasil, do ramo kwa, foram o ioruba, também chamada de Nagô, falada no sudoeste da Nigéria e no Benim, e as línguas do grupo ewe-fon, principalmente mina ou jeje.

Já, portanto, no século XVIII, existiam duas "línguas gerais" dos africanos e descendentes no Brasil: o nagô ou ioruba, vigente na Bahia, e o quimbundo nas outras regiões.

A par da influência que as línguas africanas exerceram sobre o português do Brasil, principalmente em seu aspecto lexical, não encontramos hoje nenhuma língua africana "plena" em território brasileiro. Desde o final do século XIX, as línguas africanas já se achavam reduzidas a manifestações como línguas rituais, usadas como códigos (em geral acessíveis somente aos iniciados) nas expressões culturais e religiosas, ou como falares afro-brasileiros das senzalas, dos quilombos, das minas etc., bem como falares especiais, usados por grupos específicos, expressando uma marca de identidade, como "língua secreta", como se pode ver em Cafundó (Vogt \& Fry, 1996), estado de São Paulo, e Tabatinga (Queiroz, 1998), Minas Gerais, ambas comunidades de descendentes de escravos. 


\subsection{A INFLUÊNCIA DAS LÍNGUAS INDÍGENAS E AFRICANAS SOBRE O LÉXICO DO PORTUGUÊS BRASILEIRO}

Com o objetivo de melhor conhecer o processo de diferenciação ocorrido com o português do Brasil, cabe aqui uma revisão dos principais fatos históricos que nos possam subsidiar as considerações concernentes à influência das línguas indígenas e africanas especialmente sobre o léxico do português brasileiro.

Desde o início do período colonial brasileiro já se observavam em cartas, principalmente dos jesuítas, em peças literárias ou nas crônicas de antigos historiadores, termos originários das terras brasileiras. Começava aí a primeira diferenciação da língua portuguesa na América. O Dicionário da língua portuguesa de Morais (1 ${ }^{\mathrm{a}}$ edição em 1789) já registrava razoável número de itens lexicais mais usados no Brasil do que em Portugal ou formas portuguesas já diferenciadas no território brasileiro.

Os séculos XVI, XVII e início do século XVIII ensejaram, no Brasil, a formação de um povo novo com nova cultura e nova língua. Esta era quase totalmente de uso oral, ${ }^{2}$ dada a falta de instrução pública à época, fato que só se modifica depois de 12 de setembro de 1727 , data da carta régia de $\mathrm{D}$. João V, através da qual determinou o monarca que entre as obrigações dos colonos estivesse o ensino da língua portuguesa ao índio:

Dom João, por graça de Deos, rei de Portugal e dos Algarves, daquém e dalém mar em Affrica Senhor da Guiné.

Fasso saber a vos, Superior das Missões dos Religiosos da Companhia de Jezus do Estado do Maranhão, que se tem por noticia que assim os Indios

2 "Durante três séculos, o Brasil foi, no dizer de Caio Prado Júnior, uma "vasta colônia de analfabetos”. Sem núcleos culturais capazes de irradiar um padrão idiomático, sem universidades, com um número insignificante de escolas de primeiras letras - as únicas que ensinavam o idioma -, sem imprensa (lembre-se de que o primeiro texto impresso no Brasil data de 1808, quando da transferência da Corte Portuguesa para o Rio de Janeiro), com a população realmente produtiva espalhada pelas fazendas e engenhos, a língua oral passou a seguir os seus caminhos sem nenhum controle normativo" (Cunha, 1985, p. 71). 
Filol. lingüíst. port., n. 9, p. 43-73, 2007.

que se achão Aldeiados nas Aldeias que são da administração da vossa Religião, como os que nascem nellas, e outros sim dos que novamente são descidos dos Certões, e se mandão para viverem nas dittas Aldeias, não só não são bem instruidos na Lingoa Portugueza, mas que nenhum cuidado se põe em que elles a aprendão, de que não pode deixar de rezultar hum grande desservisso de Deos e meu, pois se elles se pozerem praticos nella, mais facilmente poderão perceber os misterios da fé Catholica, e ter maior conhecimento da Ley da verdade, e com esta inteligencia, millor executarem tudo o que pertencer ao meu Real servisso, e terem maior afeição aos mesmos portuguezes, recebendo-se por este meio aquelas utilidades que se podem esperar dos dittos Indios, seguindo-se ahinda maiores se os inclinarem a aprender a trabalhar nos Officios mecanicos, pois a muito menor preço terão as suas obras os moradores do ditto Estado... (Conselho Ultramarino, Arq. 1.2.33. (Instituto Histórico e Geográfico Brasileiro), apud Castro, 1986, p. 307)

Releva ainda salientar que foi no reinado de D. João V, monarca que se comprazia em ter a companhia de intelectuais, que se deu o advento da consciência de posse de uma língua nacional em Portugal, fato para o qual muito contribuiu o padre teatino francês Rafael Bluteau, um dos conselheiros do rei em matéria linguíística, como se vê pelo seu próprio depoimento acerca do estado da língua portuguesa:

\footnotetext{
Também houve quem com rústica simplicidade me disse que não merecia a língua portuguesa tanto trabalho. A razão deste disparate é que, na opinião da maior parte dos estrangeiros, a língua portuguesa não é língua de per si, como é o francês, o italiano, etc., mas língua enxacoca e corrupção do castelhano, como os dialetos, as linguagens particulares das províncias, que são corrupções das línguas, que se fala na corte e cabeça do reino... Sobre esta errada apreensão tenho tido grandes debates com estrangeiros de porte e literatos. A razão em que se fundam é que muitos vocábulos portugueses são radicalmente castelhanos, mas truncados e diminutos; falta que (segundo eles dizem) denota a sua pouca derivação. (Braga, Curso de história da literatura portuguesa, 1885, p. 330, apud Castro, 1986, p. 314).
}

Por essa época, primeira metade do século XVIII, os portugueses do continente europeu já falavam em um dialeto brasileiro, conquanto, na Europa, o conceito de dialeto fosse usado, provavelmente, desde o século XVI. 
FERRAZ, Aderlande Pereira. O panorama linguiístico brasileiro: a coexistência de línguas...

Na França, aparece pela primeira vez, no sentido de linguagem regional, em 1550, com o poeta Ronsard. Na Espanha, segundo Corominas, em 1604. Em Portugal, segundo o dicionarista Antônio de Moraes e Silva, ainda no século XVII. (...) O tardio aparecimento do termo dialeto em Portugal é, por si só, um indicador eloqüiente da inexistência, até fins do século XVII, da consciência de uma língua nacional, como existia na Inglaterra, França e Espanha desde a primeira metade do século XVI. (Castro, 1986, p. 311-2)

Com a concepção de dialeto predominante à época "corrupção da língua que se fala na corte" -, Jerônimo Contador de Argote, padre teatino e, como Rafael Bluteau, membro da Academia Real da História Portuguesa e conselheiro de D. João V em assuntos linguísticos, apresenta, em 1725, sua definição de dialeto da língua portuguesa:

Mestre. Que quer dizer Dialecto?

D. Quer dizer modo de fallar.

M. Que cousa he Dialecto?

D. He o modo diverso de fallar a mesma lingua.

M. Dizey exemplo.

D. O modo, com que se falla a lingua portugueza nas terras v.g. da Beyra, he diverso do com que se falla a mesma lingua Portugueza em Lisboa porque em huma parte se usa de humas palavras, e pronuncia, e em outra parte se usa de outras palavras, e outra pronuncia, não em todas as palavras, mas em algumas. Esta diversidade pois de fallar, que observa a gente da mesma lingua, he que se chama Dialecto.

(...) M. há mais algum Dialecto?

D. Há os Dialectos ultramarinos, e conquistas de Portugal como India, Brasil, \&C. os quaes tem muytos termos das

linguas barbaras, e muytos vocabulos do Portuguez antigo. (Contador de Argote, Regras da língua portuguesa, 1725, p. 291 e 300, apud Castro, 1986, p. 315).

Como se vê, a definição de dialeto em Contador de Argote é realçada sobre a diferenciação lexical, o que no caso do Brasil recai sobre os brasileirismos, como se depreende do último período da citação acima.

O reconhecimento, portanto, dos brasileirismos foi ponto capital para se considerar, no século XVIII, o português do Brasil como um dialeto. Esse pensamento fez doutrina e, com o passar do tempo, foi encontrar eco em Leite de Vasconcellos, a par de vários 
estudiosos dos assuntos de língua, sobretudo no início do século XX, saírem em defesa dessa tese.

José Leite de Vasconcellos, importante etnólogo e filólogo português, em sua obra Esquisse d'une dialectologie portugaise, tese de doutorado apresentada na Faculdade de Letras da Universidade de Paris e publicada em 1901, com segunda edição em 1970, ao tratar das principais variedades da língua portuguesa, sob a perspectiva dialetológica (dialectes continentaux, dialectes insulaires e dialectes d'outremer etc.), faz uma descrição do português do Brasil, o qual, designado como dialeto brasileiro (dialecte brésilien), é considerado pelo autor como o resultado da evolução do português continental, a partir do período colonial, justificando assim o seu conceito, fundamentado, nesse caso, num critério histórico.

Alguns anos após vir a lume a primeira edição da Esquisse, de Leite de Vasconcellos, à época em que a Academia Brasileira de Letras recebia de uma comissão de notáveis o projeto de reforma da ortografia acadêmica, 25 de abril de 1907, Silva Ramos, membro desta comissão e professor do colégio Pedro II, assim expressava seu pensamento sobre o português do Brasil:

\footnotetext{
A dialetação, como bem sabeis, é um fenômeno natural que a ninguém é dado acelerar ou retardar, por maior autoridade que se arrogue: ao tempo e só ao tempo, é que compete produzi-lo. As línguas românicas foram dialetos do latim, um dos dialetos, por sua vez, do ramo itálico, dialeto ele próprio da língua dos árias; não pode haver, portanto, dúvida mínima, para quem aprendeu na aula de lógica a introduzir, que o idioma brasileiro, de dialeto português que ainda é, chegará a ser um dia a língua própria do Brasil. (Anuário do colégio Pedro II, 4, p. 152-3, 1918-19, apud Castro, 1986, p. 354)
}

Entretanto, se de um lado houve aqueles que, até as primeiras décadas do século XX, com referência ao português do Brasil, empregavam termos como dialeto brasileiro, luso-brasileiro, lusoamericano, neoportuguês, brasileiro, idioma brasileiro etc. (Pinto, 1978), geralmente considerando padrão a modalidade portuguesa; no Brasil, houve também aqueles que, no afã de manter viva a chama da brasilidade e contaminados pelo vírus do nacionalismo linguíístico, pugnaram por uma língua autônoma, uma "língua brasileira". 
Nesse contexto, é inegável a contribuição dos autores românticos e da corrente dos "vocabulistas", atestando formas do acervo lexical do português do Brasil.

No caso da literatura brasileira, antes mesmo do Romantismo, cabe ressaltar a figura emblemática de Gregório de Matos, século XVII, que se tornara o primeiro escritor verdadeiramente nacional, assim considerado, sobretudo, pela profusão de termos de origem indígena e africana em sua lavra poética.

Todavia, é no Romantismo que a presença de termos regionais, indígenas e africanos se destacam com amplitude. Gonçalves de Magalhães, ao introduzir o Romantismo em terras brasileiras, já o fez com o tema do índio.

Gonçalves Dias e José de Alencar, os dois expoentes do indianismo brasileiro, conferiram às palavras de origem tupi a mesma importância dada aos vocábulos considerados essencialmente literários, como os eruditos de procedência latina. Ambos os autores estudaram a língua tupi, sendo que Gonçalves Dias chegou a publicar um dicionário da língua tupi (Diccionário da Língua Tupy, chamada Língua Geral dos índios do Brazyl. Leipzg, F. A. Brockaus, 1858), do qual muito se valeu Alencar.

Autores outros, como Olavo Bilac, Bernardo Guimarães, Machado de Assis, também lançaram mão, ainda que em menor escala, de termos indígenas. Bilac, no poema "A Morte do Tapir", usa treze substantivos comuns e três nomes próprios da língua tupi.

Quanto ao uso de vocábulos originários de línguas africanas por autores brasileiros, importa mencionar Raimundo Correia, Jorge de Lima, Guilherme de Almeida e, principalmente, Coelho Neto, que, apresentando em sua obra ficcional várias personagens negras, dá um grande destaque a esse vocabulário.

Abrangendo campos semânticos diversos, as palavras de origem indígena e africana usadas por todos esses autores respondem por grande parte das incorporadas ao acervo lexical efetivo, atualizado, do português do Brasil, como podemos notar pelos seguintes exemplos: 
Filol. lingüíst. port., n. 9, p. 43-73, 2007.

a) tupinismos - nomes de pessoas e de lugares: Araci, Aracaju, Avaí, Caraguatatuba, Guanabara, Guaporé, Jabaquara, Jacarepaguá, Jundiaí, Moema, Niterói, Parati, Piracicaba, Tijuca;

nomes de plantas e de animais: arara, abacaxi, araticum, buriti, caju, capim, capivara, carnaúba,

cipó, cupim, curió, imbuia, ipê, jaboticaba, jacarandá, mandacaru, mandioca, maracujá, piranha, quati, sucuri e tatu;

nomes comuns: arapuca, caatinga, catapora, moqueca; capinar, empipocar etc.;

b) africanismos - a maioria dos vocábulos procede do nagô ou ioruba (grupo sudanês) e do quimbundo (grupo banto): Bangu, Carangola, Caxambu, Iemanjá, (nomes próprios); acarajé, cachumba, caçula, cafuné camundongo, chuchu, cachimbo, dendê, fubá, maxixe, molambo, moleque, samba, senzala (nomes comuns); batucar, cochilar, xingar etc.;

c) vozes ameríndias - umas poucas palavras oriundas de outras línguas indígenas brasileiras que não o tupi: Maceió, Xiquexique etc; oriundas de línguas americanas não-brasileiras: canoa, cacique, bagre, gaúcho, cacau, chácara, mate etc.

A influência indígena sobre o léxico do português brasileiro ainda pode ser observada em expressões como andar na pindaíba, estar (ficar) de tocaia etc.

\section{OS IMIGRANTES EUROPEUS $\in$ ASIÍTICOS}

O século XIX foi marcado por uma enorme campanha imigratória movida pelo governo imperial do Brasil, a qual ganhou força maior com a extinção do tráfico de escravos, em 1850, e o fim da escravidão, em 1888, quando a economia do país passou a ressentir-se da falta de mão-de-obra. Com o objetivo de sustentar e desenvolver as atividades econômicas do país, a imigração foi estimulada pelo Governo Federal em finais do século XIX e início do XX, favorecendo a contratação em massa de imigrantes europeus e asiáticos.

A criação de centros de colonização, principalmente nos estados da região Sul, e a necessidade crescente de mão-de-obra para o cultivo do café, especialmente no estado de São Paulo, foram os pontos norteadores da campanha imigratória, que levou o Brasil a oferecer transporte marítimo gratuito, financiar a fixação do imigrante em glebas doadas, favorecendo-o com incentivos fiscais animadores: 
FERRAZ, Aderlande Pereira. O panorama linguiístico brasileiro: a coexistência de línguas...

\begin{abstract}
Nos primeiros contratos o governo imperial prometeu aos colonos o pagamento das passagens, a cidadania brasileira, a cada chefe de família uma propriedade com área aproximada de 75 hectares, conhecida como uma colônia, sementes e gado necessários para o início do plantio e da criação e, durante o primeiro ano, a diária de 160 réis, reduzida à metade no segundo ano, além da isenção de impostos pelo período de dez anos, durante o qual não podiam alienar a propriedade. (Staub, 1983, p. 18)
\end{abstract}

No Brasil, com exceção do português, língua dos imigrantes portugueses que vieram em grande número para cá desde o período da Independência do Brasil, as línguas dos imigrantes europeus e asiáticos constituem línguas minoritárias, núcleos linguiísticos situados principalmente nas regiões Sul e Sudeste. A introdução dessas línguas estrangeiras no Brasil ocorreu em diversas etapas e em diferentes períodos históricos, começando com as línguas de origem européia. Dentre essas, podemos destacar o alemão, o espanhol, o italiano, o polonês, o holandês, o inglês, o leto etc. Das línguas asiáticas, é possível citar o árabe, o japonês, o chinês, o coreano etc.

\title{
4. 1 AS LÍNGUAS DOS IMIGRANTES ASIÁTICOS
}

A partir da visita de D. Pedro II ao Líbano, em 1876, os árabes, especialmente libaneses, começaram a chegar ao Brasil, fixando-se em terras brasileiras com o apoio do então imperador. Em 1880, novo grupo de libaneses aportou no Rio de Janeiro e, entre 1910 e 1940, eles instalaram-se principalmente no estado do Espírito Santo, além de algumas cidades no estado de São Paulo.

No início do século XX, enquanto sobrava mão-de-obra no Japão, o Brasil vivia um momento de grande carência de trabalhadores para a lavoura cafeeira, então em expansão. O vapor Kasato Maru, que aportou em Santos em 18 de junho de 1908, chegou transportando os primeiros japoneses, 781 imigrantes, indivíduos de diferentes regiões do Japão, contratados para o trabalho com a lavoura de café, em fazendas brasileiras, principalmente as paulistas. Até o início da Segunda Guerra Mundial, cerca de 190 mil imigrantes japoneses deram entrada no Brasil e, hoje, estima-se que a colô- 
nia japonesa ultrapasse o número de um milhão de pessoas, incluindo descendentes de segunda, terceira e quarta gerações.

A língua japonesa falada no Brasil reflete a mescla de dialetos de diferentes regiões do Japão, com predominância de um ou outro, de acordo com a procedência regional e o número de falantes. Essa língua, também chamada koronia-go ("língua da colônia”), é considerada por muitos falantes de japonês no Brasil como o japonês antigo misturado com o português brasileiro. É importante salientar que o uso da língua japonesa no Brasil não se restringe à comunicação oral entre os membros da comunidade nipo-brasileira. A língua escrita tem sido usada em diversas publicações, muitas avulsas e artesanais, mas também de jornais, como o São Paulo-Shimbun. Decorrente do contato entre as línguas portuguesa e a japonesa no território brasileiro, é possível verificar a presença em nossa língua de itens lexicais, representando vários segmentos da cultura japonesa, como sushi, sashimi, tempura, shoyu, shiitake (na gastronomia), judô, jiu-jitsu, karaokê (esportes e lazer), tatami, furô, quimono (costumes) etc.

Dos imigrantes asiáticos que aportaram no Brasil, é importante destacar ainda a colônia chinesa no Brasil, sobretudo no estado de São Paulo, composta por chineses de várias províncias da China. Como em território chinês, a diferenciação dialetal é bastante acentuada; tal fato tem permitido considerar os chineses e seus descendentes, no Brasil, uma comunidade diglóssica. É que essa comunidade usa, no Brasil, além do chinês-padrão, vários dialetos regionais. Em verdade, os imigrantes chineses utilizam em nosso território o bilingüismo chinês/português e o chinês-padrão com algum dos dialetos, dependendo da situação, do ambiente ou dos interlocutores.

Os imigrantes cantoneses usam principalmente o cantonês para comunicação entre si, mas usam o português na comunicação com os filhos.

Os imigrantes taiwaneses ou min do Sul, com exceção de pessoas de mais idade, falam normalmente o chinês-padrão, alternando com o dialeto, quando se dirigem aos familiares e amigos. 
Os hakka em geral conservam firmemente o uso de seu dialeto em família, usando o chinês-padrão apenas com pessoas de outras províncias.

Imigrantes vindos de Shanghai ou Zhejiang, com exceção dos que se casam com pessoas de outras províncias, usam basicamente o dialeto wu, reservando o chinês-padrão apenas para a comunicação com pessoas de outras províncias.

Enfim, muitos imigrantes de primeira geração, que vivem no Brasil há mais de trinta ou quarenta anos, usam principalmente o português com suas famílias, mas, quando em contato com outros chineses, utilizam o chinês-padrão ou algum dialeto.

\subsection{AS LIINGUAS DOS IMIGRANTES EUROPEUS}

A campanha imigratória movida pelo governo imperial do Brasil, no século XIX, chegou à Europa, dando ensejo a uma onda imigratória que foi um fenômeno em massa de grandes proporções, decorrente de condições sócio-históricas propícias nos dois lados do Atlântico, intermediadas pelas Companhias de Navegação e de Imigração.

Em meio às várias línguas européias que chegaram ao Brasil, cumpre citar a língua holandesa, falada ainda hoje no interior paulista. Depois do primeiro contato com o Brasil, no século XVII, quando houve a tentativa de colonização do país por parte dos holandeses, a imigração holandesa ocorreu no século XX, com uma leva de aproximadamente vinte mil falantes de holandês, que adquiriram glebas, especialmente no estado de São Paulo, onde hoje está a cidade de Holambra e onde a comunidade de descendentes mantém o uso da língua holandesa.

A imigração alemã, que iria marcar fortemente a cultura de alguns estados brasileiros, ocorreu no Brasil em várias etapas, a partir de 1824. Os imigrantes falantes de alemão que vieram para o Brasil, procedentes da Alemanha, da Suíça, da Áustria e alguns da Rússia, 
organizaram-se aqui em pequenos grupos e no interior destes mantinham seus dialetos locais. É importante salientar que até 1937, nas colônias alemãs, todo o ensino se fazia em alemão. Atualmente, podemos encontrar a língua alemã, com seus vários dialetos, incluindo o Hochdeutsch, alemão padrão, sendo falada nos estados do Paraná (Rio Negro, Ponta Grossa, Rolândia, Entre Rios), Santa Catarina (Blumenau, Joinville, São Francisco do Sul, Brusque, Itajaí, São Bento) Espírito Santo (Santa Leopoldina) e Rio Grande do Sul (São Leopoldo, Santa Augusta, São Lourenço, Lageado, Montenegro).

A imigração italiana, com um número bastante expressivo de imigrantes que aportaram no Brasil, também contribuiu para marcar fortemente as tradições culturais de alguns estados brasileiros. Os imigrantes italianos, vindos a partir de 1870 , fixaram-se em centros urbanos (capital e interior) e em fazendas de café, formando em seguida os núcleos coloniais. Os falantes de italiano e de variedades dessa língua instalaram-se, predominantemente, nas regiões Sul e Sudeste, e estima-se em $70 \%$ o contingente de imigrantes que se teria radicado no estado de São Paulo. Em alguns núcleos coloniais nas regiões Sul e Sudeste, algumas variedades de italiano continuam sendo faladas até hoje. Importa citar o estudo de Leme (2001) sobre uma variedade misturada de dialetos italianos (o tirolo e o trentino) com o dialeto caipira do português na região de Piracicaba, revelando, assim, a influência da língua portuguesa sobre a língua italiana falada nessa região.

Das línguas dos imigrantes europeus, todavia, queremos destacar aqui, em especial, a situação que envolve a língua polonesa.

\subsubsection{A IMIGRAÇÃO POLONESA}

Quase a totalidade dos emigrantes poloneses que optou pela vida no Brasil constituía-se de camponeses: pequenos proprietários (minifundiários) e arrendatários (provenientes das aldeias mais isoladas e conservadoras) que ansiavam pela posse de terras brasileiras, já que não vislumbravam qualquer perspectiva otimista em 
meio à desagregação da economia agrária por que passava a sociedade polonesa.

A emigração polonesa para o Brasil ocorreu em vários períodos, desde 1869, quando dezesseis famílias vieram para Santa Catarina, instalando-se na colônia Brusque (Stawinski, 1976, p.15, apud Druszcz, 1984, p. 16), em 1890, quando emigraram grupos procedentes da região sob ocupação russa, e 1895, quando se deslocaram grupos da Galícia, região sob o domínio austríaco.

A emigração em massa para o Brasil, entretanto, relaciona-se com o episódio que passou a ser denominado goraczka brazylijska (a febre brasileira):

\footnotetext{
O maior afluxo de imigrantes poloneses ocorre no período compreendido entre 1890 até a Primeira Guerra Mundial. Nesse período, o surgimento de escriturários de recrutamento de imigrantes e a propaganda dos chamados 'agentes' de colonização, que prometia passagem gratuita e terra no Brasil, país que era descrito com cores exageradas como um fantástico paraíso, agitou as aldeias polonesas e levou tanta gente a emigrar ao Brasil que esse período chegou a ser chamado de "febre brasileira". (Kawka, 1982, p. 13)
}

Nesse período de intenso movimento emigratório, grandes grupos de poloneses chegaram ao Brasil, fixando-se nos estados de Santa Catarina, Rio Grande do Sul, Paraná, São Paulo, Espírito Santo e Minas Gerais. Contudo, a maioria radicou-se nos três primeiros estados, tendo o Paraná recebido maior número, de sorte que em 1983 contava com cerca de 384.212 poloneses e seus descendentes (Druszcz, 1983, p. 17); em todo o Brasil, segundo dados estatísticos apresentados por Mariano Kawka em 1982, haveria cerca de um milhão (Kawka, 1982, p. 17).

\subsubsection{AS COLÔNIAS POLONESAS: LÍNGUA E CULTURA}

O primeiro grupo de imigrantes poloneses, que chegou a Santa Catarina em 1869, se transferiu para o Paraná, radicando-se na colônia de Pilarzinho, atualmente bairro de Curitiba. 
Em 1873, um grupo de 258 imigrantes fixou-se na colônia de Abranches, também bairro de Curitiba atualmente.

Em 1875, outro grupo de poloneses, procedente da região da Silésia, fundou a colônia Santa Cândida, nos arredores de Curitiba; em 1876, 390 imigrantes provenientes da região da Pomerânia e da Silésia instalaram-se nas colônias de Santo Inácio e Órleans. Ainda no mesmo ano, chegou à colônia de Tomás Coelho, município de Araucária, um grupo, na sua maioria galicianos, procedente da Galícia e da Silésia. Já em 1878, cerca de 500 imigrantes poloneses fixaramse na colônia Inspetor Carvalho e outros tantos buscaram o município de São José dos Pinhais e fundaram a colônia Murici (arredores de Curitiba).

Como a maioria dos imigrantes poloneses se constituía de agricultores, acostumados, desde há muitas gerações, ao amanho da terra, muitos dos que foram chegando aos arredores de Curitiba logo sentiram-se atraídos pelo interior do estado e buscaram o sertão inculto, desdenhando as oportunidades de vida urbanizada, no afã de satisfazer a sua extraordinária sede de terras.

Várias outras colônias polonesas foram então surgindo em todo o estado do Paraná, como a colônia de São Mateus, às margens do rio Iguaçu, onde os poloneses chegaram em agosto de 1891; a colônia de Água Branca, fundada a 20 quilômetros de São Mateus; e mais adiante as colônias de Rio Claro, Sede Iguaçu e Vera Guarani, onde além da população de origem polonesa, contam-se também pessoas de origem ucraniana.

Politicamente Rio Claro pertence a Mallet, mas economicamente ninguém sabe, porque da cidade sede de Mallet é separada pelas montanhas da Serra do Tigre. Por isso os moradores permanecem aqui como que isolados e esta deve ser a única colônia no Brasil construída segundo o modelo das aldeias polonesas, e até hoje conserva esse aspecto. Vera Guarani e Sede Iguaçu estão situadas ao sul de Rio Claro, e são famosas pela atividade social nos tempos coloniais, graças à iniciativa dos cidadãos do lugar. (Wachowicz, 1984, p. 11) 
A vida social nas colônias polonesas sempre se pautou pela conservação da cultura, da língua, da religião e dos hábitos peculiares a cada aldeia de origem dos imigrantes.

\begin{abstract}
Em 1903, a pedido do bispo de Curitiba, chegaram da Polônia os padres da congregação de $\mathrm{S}$. Vicente de Paulo, conhecidos também como lazaristas ou vicentinos. Na mesma época (1904) estabeleceram-se em Curitiba os padres da Sociedade do Verbo Divino, chamados verbistas. Esses padres fundaram inúmeras paróquias pelas colônias polonesas do Paraná, Santa Catarina e Rio Grande do Sul, contribuindo para aglutinar em torno da igreja a vida comunitária polonesa. Ao mesmo tempo, a vinda de membros de congregações religiosas femininas da Polônia, como as irmãs de S. Vicente de Paulo em 1904 e as irmãs da Sagrada Família em 1906, veio reforçar a atuação do clero polonês nas colônias. (Kawka, 1982, p. 23)
\end{abstract}

Em face disso, a religião passou a constituir um elemento importante entre os fatores que contribuíram para a preservação da língua polonesa entre os imigrantes e seus descendentes no Brasil.

Em 1876, juntamente com a fundação da colônia Órleans, surgiu a primeira escola polonesa no Paraná, dirigida por Jerônimo Durski, conhecido por "Pai das Escolas Polonesas". Logo após, outras escolas foram abertas, espalhando-se por quase todas as colônias, desfazendo as preocupações dos imigrantes quanto ao problema da alfabetização (em polonês) de seus filhos.

Inicialmente, o ensino nessas escolas era praticado em polonês; algum tempo depois se tornou bilínguie, quando as escolas passaram a ensinar Língua Portuguesa e História do Brasil, concomitantemente ao ensino da Língua Polonesa e História da Polônia.

As escolas polonesas atuaram com essa forma de ensino até 1937, momento em que foram atingidas pela determinação do Governo Federal, nacionalizando o ensino particular estrangeiro no Brasil.

De conformidade com Kawka (1982, p. 27), em 1937, véspera da nacionalização do ensino, era a seguinte a situação das escolas polonesas no Brasil: 
Filol. lingüíst. port., n. 9, p. 43-73, 2007.

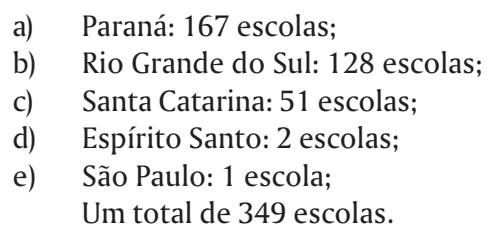

E com relação ao uso das línguas polonesa e portuguesa, o número de escolas do Paraná se dividia entre aquelas que mantinham:

\footnotetext{
a) uso exclusivo do polonês: 10 escolas;

b) uso exclusivo do português: 14 escolas;

c) uso alternado do polonês e do português: 143 escolas.
}

Importa acrescentar ainda que, concomitantemente à onda de escolarização entre os imigrantes poloneses, desenvolveu-se um grande movimento de atividades culturais nas colônias, com a criação de vários grupos teatrais, corais e grupos folclóricos.

E em 1892, em Curitiba, foi fundado o primeiro jornal em língua polonesa publicado no Brasil, por Karl Szulc, denominado Gazeta Polska w Brazylii (“Jornal Polonês no Brasil”), circulando até 1941.

Entre 1892 e 1941 circularam no Brasil cerca de 60 periódicos em língua polonesa, alguns de vida efêmera, outros conseguindo subsistir por muitos anos. Entre estes últimos sobressai o jornal "Lud" ("O Povo"), fundado em 1920 e pertencente aos padres da congregação da Missão. Fechado em 1940 em consequiência do decreto de nacionalização, ressurgiu em 1947 e circula até o dia de hoje como jornal semanário. (Kawka, 1982, p. 32)

Além de jornais, a comunidade polono-brasileira tem publicado boletins, revistas e almanaques em polonês, constituindo todo esse acervo em grande contributo para a história da colonização polonesa no Brasil, a par de ter sido recurso de preservação da língua polonesa entre os imigrantes e seus descendentes. 


\subsubsection{PRESERVAÇÃO DA LÍNGUA POLONESA: SENTIMENTO NACIONAL EIDENTIDA- DELINGÜÍSTICO-CULTURAL}

Discutindo os aspectos que contribuem para a preservação das línguas minoritárias, Appel \& Muysken (1987) reafirmam as colocações de Giles, Bourhis e Taylor (in Giles et al., 1977), segundo as quais a manutenção ou mudança de códigos linguiísticos numa comunidade de fala depende da vitalidade etnolingüística. De sorte que com relação aos falantes de línguas minoritárias, uma alta vitalidade etnolinguiística lhes garantiria a preservação das mesmas, ao passo que uma baixa vitalidade etnolinguiística lhes propiciaria a assimilação da língua majoritária, ou a substituição da sua por esta.

De acordo com Appel \& Muysken (1987), a vitalidade etnolinguiística compreende a combinação de três fatores principais: o status, a demografia e o suporte institucional.

O status deve ser compreendido em quatro aspectos:

a) Status econômico: diz respeito à estabilidade econômica, sobretudo quando o sucesso econômico se relaciona à língua da comunidade de fala. Todavia, quando falantes de línguas minoritárias têm um poder aquisitivo relativamente baixo, podem apresentar uma forte tendência em assimilar a língua majoritária, se essa lhes acena com melhores possibilidades de sucesso econômico.

b) Status social: refere-se ao prestígio que uma determinada língua goza, decorrente de sua importância no cenário social onde é falada. Em face disso, o fato de falantes de línguas minoritárias não saberem ou não usarem a língua majoritária, quando esta é a principal ou única língua do comércio e da indústria, dos setores públicos, da escola, enfim, de comunicação oficial, implicaria sérios entraves a seu crescimento social nessa comunidade.

c) Status sócio-histórico: decorrente da história etnolinguiística de cada grupo.

d) Status lingüístico: está relacionado com o status social. Um grupo minoritário poderá considerar baixo o seu status lingüístico se, por exemplo, falar um dialeto de menos prestígio social. 
O fator demográfico refere-se ao número de falantes de uma língua minoritária e sua distribuição geográfica. A situação torna-se preocupante, no que concerne à preservação da língua, quando esse número de falantes começa a decrescer, ou quando deixa de viver nas mesmas áreas, dispersando-se, ao contato com grupos diferentes.

\footnotetext{
Quando as vicissitudes de uma comunidade humana acarretam sua divisão em duas ou mais subcomunidades ou novas comunidades, reduz-se o contato entre as pessoas separadas nessas novas comunidades e, em consequiência, diminui a necessidade de ajuste e aumenta a diferenciação linguiística entre os grupos humanos correspondentes. Se as novas comunidades, resultantes da divisão do que foi antes uma só comunidade com uma só língua, distanciam-se no espaço geográfico e perdem de todo o contato entre si, desaparece inteiramente a necessidade de ajuste comunicativo entre elas. Nesse caso, as alterações linguiísticas que ocorrem em cada comunidade não serão mais reajustadas em comum e, por descoincidirem em muitos casos, vão constituir diferenças entre suas falas. Estas se tornarão línguas diferentes, na medida em que o correr do tempo expuser uma e outra, independentemente, às circunstância mais variadas. (Rodrigues, 1986, p. 18)
}

Cabe lembrar aqui a situação canadense, mais especificamente a região de Québec, onde muitos falantes de francês permanecem concentrados, e, por isso mesmo, tem a língua francesa ali permanecido com grande vitalidade, ao passo que em outras partes do Canadá, onde os falantes de francês vivem mais dispersos, é possível observar uma tendência à mudança de código em direção ao monolingüismo em inglês (Lieberson, 1970).

O suporte institucional é outro fator de grande importância para a vitalidade etnolinguiística.

A preservação de uma língua minoritária poderá ser mantida quando essa língua é usada em vários setores institucionais, quais sejam: governo, escola, igreja, organizações culturais etc.

À face do exposto, pode-se ressaltar os principais fatores que propiciaram a preservação da língua polonesa em território brasileiro, do início da imigração aos dias atuais.

A elevada vitalidade etnolinguiística dos poloneses e seus descendentes, radicados no Brasil, pode ser entendida, primeiramente, pelo suporte institucional. 
Como a imigração polonesa no Brasil ocorreu em massa e não individualmente, o surgimento de colônias foi inevitável, ensejando igualmente uma vida comunitária homogênea, com a preservação da cultura popular.

A língua polonesa, portanto, mantinha seu suporte institucional dentro das colônias, sendo utilizada no ambiente doméstico, nos cultos religiosos, nas atividades culturais ou folclóricas, na imprensa e na escola polonesa.

Convém assinalar ainda que o isolamento de muitas colônias também contribuiu para o retardamento da aculturação dos poloneses.

A par disso, também o fator demográfico deve ser considerado quanto à vitalidade etnolinguiística dos poloneses no Brasil, ressalvando-se que a imigração não se deu de uma só vez, mas em várias etapas, de 1869 até a Segunda Guerra Mundial, o que permitiu que cada grupo de poloneses que aqui se fixava influísse decisivamente, como os seus descendentes, no fortalecimento da cultura, e da língua em particular, elevando progressivamente o número de falantes de polonês.

No que concerne ao status sócio-histórico, convém seja aqui destacado o grande espírito nacionalista dos poloneses.

Provavelmente, pelo fato de ter vivido um longo período de dominação estrangeira (de 1772 até o final da Primeira Guerra Mundial), sob forte opressão e perseguição à sua cultura, o povo polonês tenha desenvolvido tão acendrado sentimento nacionalista, como se a conservação desse nacionalismo lhes substituísse a independência perdida.

O isolacionismo e a não-miscigenação com outros grupos étnicos tornavase então uma obrigação patriótica, cujo cumprimento era condição para a preservação da nacionalidade. A assimilação identificava-se com a traição da pátria. (...) Esse espírito nacionalista, chamado pelos poloneses de "polskosc" (polonidade), tem como uma de suas manifestações a preservação do próprio idioma na terra de adoção, o que atrasa a assimilação da língua portuguesa e freia até certo ponto o próprio processo da dialetização. (Kawka, 1982, p. 19) 
Contudo, algum tempo após o início da imigração, os poloneses já podiam sentir que a necessidade força o caminho da interação.

No afã de melhorar o status econômico e o status social, uma razão utilitária (Fishman, 1966, p. 129) os levaria ao desejo de aprender o português, o instrumento de comunicação mais eficiente no país. Concomitantemente, o conhecimento da língua portuguesa os integraria numa sociedade mais ampla, a brasileira, ou seja, o português identificá-los-ia, socialmente, com o povo dominante do país.

Desse modo, a escolarização, que até 1937 atuava como fator de preservação da língua polonesa entre os imigrantes e seus filhos, também propiciou o aprendizado da língua portuguesa, atuando como força contrária à manutenção do monolingüiismo em polonês.

Também o avanço dos meios de comunicação deu ensejo ao aceleramento da aculturação dos poloneses, de vez que, se o polonês predominou no período de adaptação, é possível observar hoje (guardadas as devidas proporções no campo de atuação) uma situação de bilingüismo inteiramente estabelecida.

\section{CONSIDERAÇÕES FINAIS}

O tema da diversidade cultural do Brasil permite considerar em elevada posição a situação das línguas minoritárias, presentes em território brasileiro.

Tanto o governo imperial quanto o governo republicano, assim como os fazendeiros de café, viram na imigração uma solução para diversos problemas, considerando-se que o trabalho escravo havia sido então abolido. A década de 1920, no entanto, marca o início da redução progressiva do grande fluxo de imigração em massa e, na década seguinte, problemas econômicos e políticos no país levam à redução drástica da imigração.

Em meio ao contexto nacionalista da época, o período de 1937-1939 marcou no Brasil a Campanha de Nacionalização do Ensi- 
no, política do Estado Novo, que pretendia a alfabetização e nacionalização dos núcleos coloniais, impondo aos imigrantes e seus descendentes a obrigação de aprender e falar a língua portuguesa. Tal fato veio restringir o uso das línguas maternas dos imigrantes, principalmente no domínio público institucional. Contudo, mesmo com a proibição do ensino em língua estrangeira, o que muito contribuiu para o estabelecimento do bilinguiismo entre os imigrantes, a Campanha de Nacionalização do Ensino não conseguiu evitar o uso principalmente oral das línguas para cá trazidas, o que em muitos casos perdura até hoje.

Dessa forma, a imagem romântica de um país supostamente monolíngüe, perspectivada pelo senso comum, se contrapõe a uma realidade bem diferente, no centro da qual se encontra o multilinguiismo brasileiro. Como um país pluricultural, pluriétnico e plurilínguie, o Brasil conta com mais de duzentas línguas diferentes, faladas em comunidades étnico-culturalmente diferenciadas e situadas por todo o território nacional, compostas de brasileiros que têm por língua materna uma língua indígena (autóctone), ou uma língua de imigração (alóctone), ou ainda um dos falares afro-brasileiros praticados em muitos dos quilombos que existiram no país, além das populações bilíngiies que dominam o português e uma língua indígena, ou português/alemão, português/italiano, português/polonês, português/japonês etc. À visão de um país supostamente monolíngüe, acrescente-se, ainda ao imaginário de unidade do senso comum, o mito de que a língua portuguesa falada em nosso país apresenta uma unidade monolítica, isto é, sem variação diatópica significativa, não se reconhecendo que a diversidade lingüística no Brasil compreende também a pluralidade de usos do português brasileiro.

Algumas atitudes importantes, no âmbito da política linguiística em defesa da educação bilínguie e dos direitos linguiísticos das comunidades indígenas, já foram tomadas oficialmente, garantindo os avanços conquistados. Haja vista a iniciativa da SECAD (Secretaria de Educação Continuada, Alfabetização e Diversidade), no âmbito do MEC, de promover a formação de membros das comunidades 
indígenas como professores para as escolas localizadas nas aldeias. Entretanto, no que diz respeito às línguas de imigrantes, pouco ou quase nada se fez até então, e nem mesmo mencionadas são na legislação vigente, não obstante a sua presença e representatividade no cenário nacional, amplamente destacadas.

O Brasil tornou-se, em verdade, um amplo campo de manifestações multilinguiísticas, reclamando estudos sistematizados através dos vários ramos da Linguiística. Vale lembrar aqui o apelo contido no artigo de Aryon Rodrigues (1966), em que ressalta o estudo científico das línguas indígenas como prioridade da Linguiística no Brasil:

Se é lícito falar em responsabilidade de uma comunidade com respeito à investigação científica na região em que vive essa comunidade, então os lingüistas brasileiros têm aí uma responsabilidade enorme, que é não deixar que se percam para sempre cento e tantos documentos sobre a linguagem humana. (Rodrigues, 1966, p. 5)

Enfim, cumpre reconhecer que o contato social acarreta inevitavelmente a interação linguiística, o que deve motivar estudos cada vez mais amplos sobre a realidade linguiística brasileira, considerando-se que a urgência de estudos e investigação das línguas indígenas brasileiras como das línguas de minorias européias e asiáticas em contato com o português, se faz sentir pelo risco que correm de desaparecimento os falares dos grupos minoritários, além do prejuízo que se teria, científico e cultural, por não se registrar as várias fases de contribuição desses mesmos grupos à cultura nacional.

\section{BIBLIOGRAFIA}

APPEL, R.; MUYSKEN, P. (1987) Language contact and bilingualism. London: Edward Arnold. CALVET, L.-J. (1996). Les politiques linguistiques. Paris: Presses Universitaires de France.

CÂMARA JÚNIOR, J. M. (1977) Introdução às línguas indígenas brasileiras. Rio de Janeiro: Ao Livro Técnico.

CASTRO, J. A. (1986) Formação e desenvolvimento da língua nacional brasileira. In: COUTINHO, A. (org.). A literatura no Brasil. 3. ed. Rio de Janeiro: José Olímpio, EDUFF, v. 1, p. 258-385. 
FERRAZ, Aderlande Pereira. O panorama linguiístico brasileiro: a coexistência de línguas...

CRYSTAL, D. (2000) La diversité linguistique: un atout pour l'humanité. Courrier International, 486, p. 36-7.

CUNHA, C. (1985) Língua, nação, alienação. Rio de Janeiro: Nova Fronteira.

DRUSZCZ, A. M. (1984) O bilingüismo em Araucária: A interferência polonesa na fonologia portuguesa. Dissertação (Mestrado) - Universidade Católica do Paraná.

EBNER, M. (2000) L'UE défend les langues du bout des lèvres. Courrier International, 486, p.42.

FERRAZ, A. P. (1992) Análise contrastiva do polonês da região de Cracóvia (Polônia) com o polonês da colônia Murici (Brasil). Dissertação (Mestrado) - Universidade de Brasília.

FISHMAN, J. (1971) Basic concepts, theories and problems: alternative approaches. Advances in the sociology of language. Haia: Mouton.

. (1967) Bilingualism with and without diglossia; diglossia with and without bilingualism. Journal of Social Issues, 23, 2.

. (1966) The implications of bilingualism for language teaching and language learning. In: VALDMAN, A. (org.) Trends in language teaching. New York: Mc Graw-Hill Book Company. FREIRE, J. R. B. (2004) Rio Babel: a história das línguas na Amazônia. Rio de Janeiro: EDUERJ. GOMES, M. P. (1988) Os índios e o Brasil. Petrópolis: Vozes.

GREENBERG, J. (1963) The languages of Africa. Bloomington: Indiana University.

HAUGEN, M. (1956) Bilingualism in the Americas. Alabama: University of Alabama Press.

KAWKA, M. (1982) Os brasileirismos do dialeto polono-brasileiro. Dissertação (Mestrado) Universidade Católica do Paraná.

KULA, M. (1976) Algumas observações sobre a emigração polonesa para o Brasil. Estudios Latinoamericanos. Ossolineum Warszawa: Polska Akademia Nauk-Institut Historii.

LEME, M. L. de A. (2001) Dio, che brut estudá... Um estudo lingüístico da comunidade tirolotrentina da cidade de Piracicaba. Campinas: Editora da Unicamp, Centro de Memória-Unicamp. LIEBERSON, S. (1970) Language and ethnic relations in Canada. New York: Wiley.

MELATTI, J. C. (1987) Indios do Brasil. 5. ed. São Paulo/Brasília: Hucitec.

OSMAN, S. A. (1999) A imigração árabe no Brasil. Travessia, Ano XII, 35, setembro-dezembro, p. 17-23.

PESSOA DE CASTRO, I. (2001) Falares africanos na Bahia: um vocabulário afro-brasileiro. Rio de Janeiro: Academia Brasileira de Letras/Topbooks Editora.

PINTO, E. P. (1978) O português do Brasil: textos críticos e teóricos, I - 1820/1920 fontes para a teoria e a história. Rio de Janeiro: Livros Técnicos Científicos, Edusp.

QUEIROZ, S. (1998) Pé preto no barro branco: a língua dos negros da Tabatinga. Belo Horizonte: Editora da UFMG.

RODRIGUES, A. D. (2005) Sobre as línguas indígenas e sua pesquisa no Brasil. Ciência e Cultura, 57, 2, p. 35-8. Loyola.

(1986) Línguas brasileiras: para o conhecimento das línguas indígenas. São Paulo: 
Filol. lingüíst. port., n. 9, p. 43-73, 2007.

. (1966) Tarefas da Linguíística no Brasil. Estudos Lingüísticos. Revista Brasileira de Linguiística Teórica e Aplicada, 1, 1, p. 4-15.

RODRIGUES, R. N. (1977) Os africanos no Brasil. Revisão e prefácio de Homero Pires. Notas bibliográficas de Fernando Sales. São Paulo: Nacional.

SEYFERTH, G. (1990). Imigração e cultura no Brasil. Brasília: Editora da Universidade de Brasília.

STAUB, A. (1983) O empréstimo lingüístico: um estudo de caso. Porto Alegre: Acadêmica. TARALLO, F; ALKMIN, T. (1987) Falares crioulos: línguas em contato. São Paulo: Ática.

VERMES, G.; BOUTET, J. (orgs.) (1989) Multilingüismo. Trad. Celene. M. Cruz et al. Campinas: Editora Unicamp.

VOGT, C.; FRY, P. (1996) Cafundó, a África no Brasil: linguagem e sociedade. São Paulo: Companhia das Letras.

WACHOWICZ, R. (1984) Suor em São Mateus. Anais da Comunidade Brasileira-polonesa, 9. WEINREICH, U. (1953) Languages in contact. The Hague: Mouton.

ABSTRACT: This paper constitutes a summarized presentation of an overview of the linguistic panorama in Brazil, based on a discussion of the situation of minority languages, special attention being dedicated to its development in the course of time. We also explain the present state of indigenous languages and of the language of immigrants in Brazil. Finally, we discuss linguistic diversity in present-day Brazil.

KEYWORDS: Multilingualism; minority languages; indigenous languages; the languages of immigrants. 